Supporting information for

\title{
Adsorption Behavior and Nanotribology of Amine-Based Friction Modifiers on Steel Surfaces
}

Prathima C Nalam ${ }^{1,2}$, Alex Pham ${ }^{1}$, R. Veronica Castillo ${ }^{3}$ and Rosa M. Espinosa-Marzal ${ }^{1 *}$

${ }^{1}$ Department of Civil and Environmental Engineering, University of Illinois at UrbanaChampaign, Urbana 61801, Illinois, USA

${ }^{2}$ Department of Materials Design and Innovation, University at Buffalo, NY, USA

${ }^{3}$ Centre de Recherche de Solaize -Chemin du Canal, Total Marketing Services, BP 22-69360 Solaize, France

* Corresponding Author: rosae@illinois.edu 


\section{Supporting Information 1:}

To explore the preferential interaction between $n$-hexadecane and steel surface, if any, a series of solvents were exchanged through the QCM cell. The frequency change normalized by solvent density plotted as a function of the decay length of the shear wave originated at the crystal surface, after each solvent exchange, is presented in Figure 4 at different overtones. The solid line represents the theoretical linear relation between the frequency change and the decay lengths as discussed by refs. [1,2]. The good agreement between the experimental data and the theoretical line indicates both the absence of interactions of the solvents (including n-hexadecane) with the surface and that the steel-coated quartz crystals employed in these measurements are sufficiently smooth (RMS $\sim 0.9 \mathrm{~nm}$ from AFM imaging).

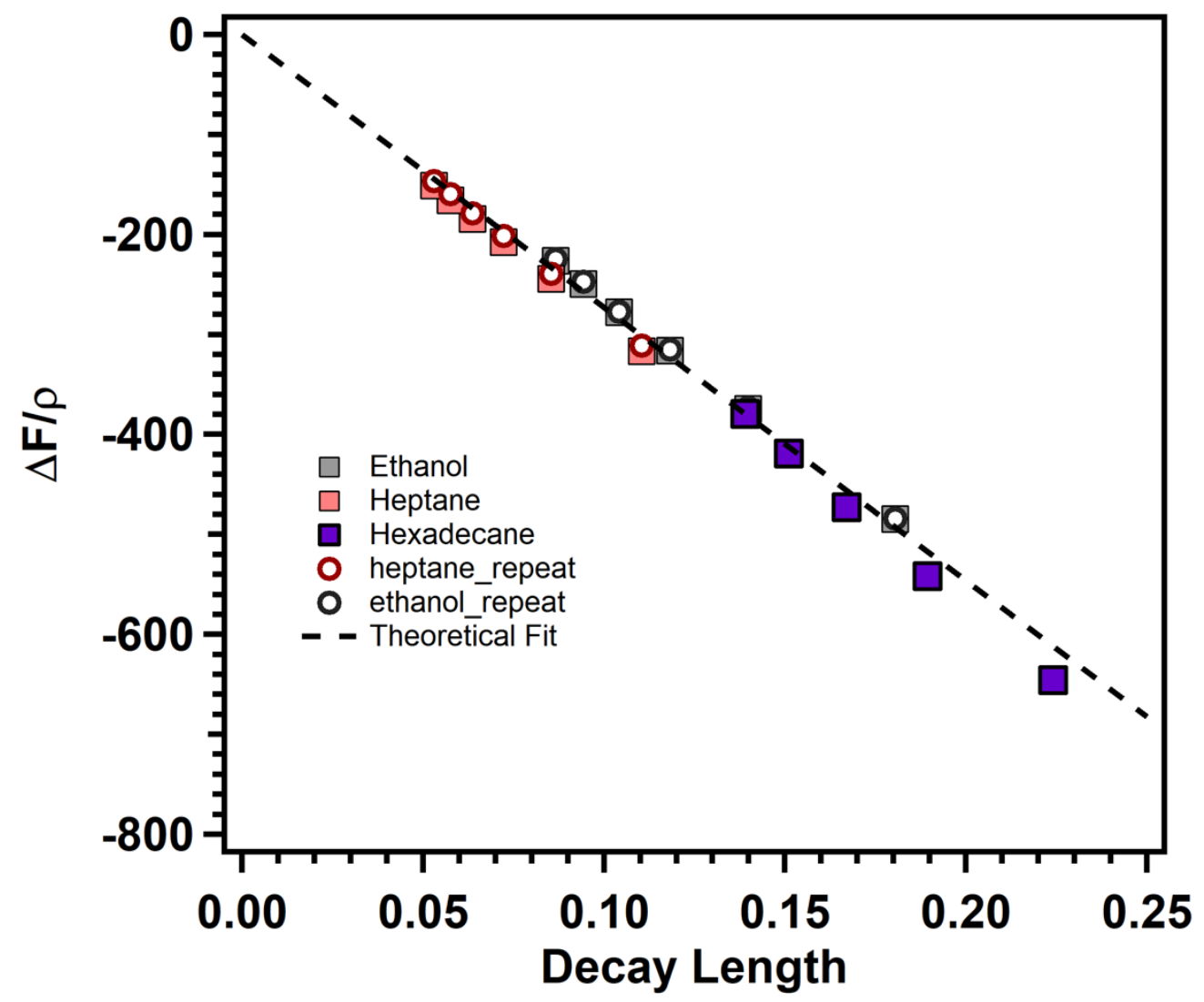

Figure S1: Changes in frequency normalized by density obtained in each solvent over bare steel crystal vs. decay length of the acoustic wave from the crystal surface. 


\section{Supporting Information 2:}

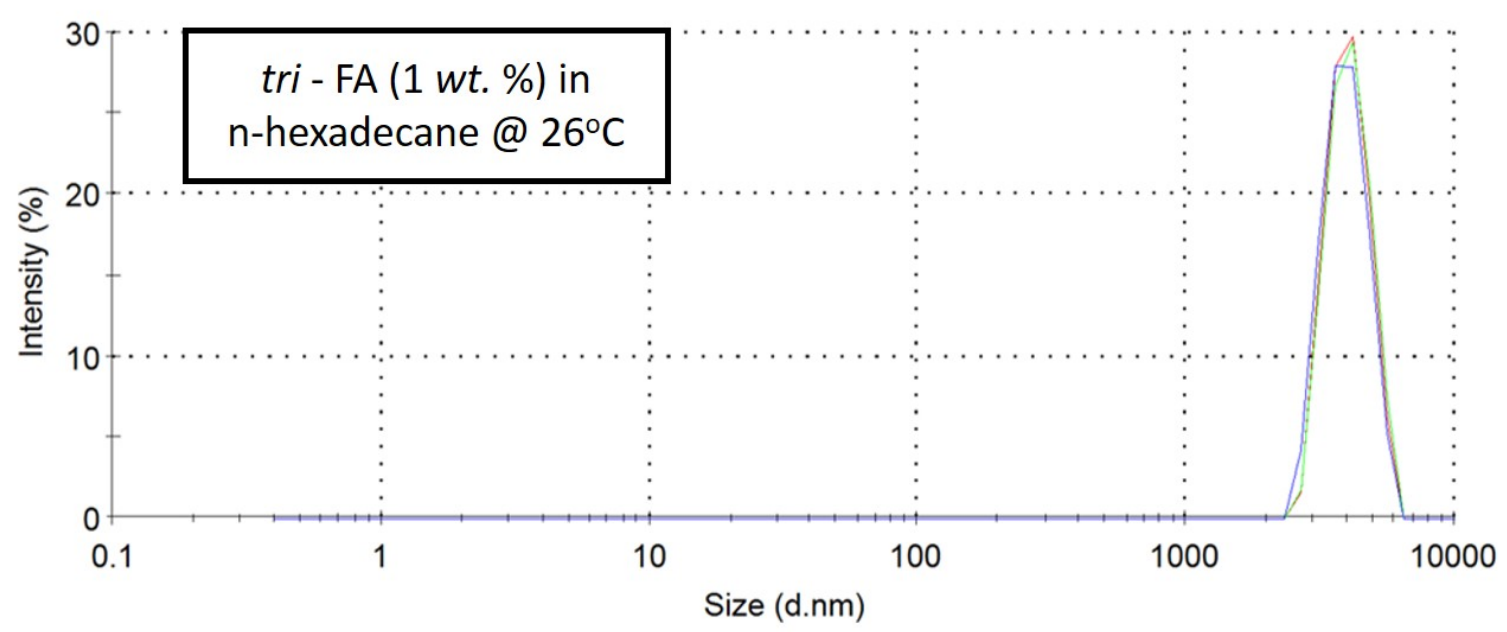

Figure S2: Light scattering (in intensity \%) of tri-FA in n-hexadecane (Concentration: 1 wt. \%) measured at $26^{\circ} \mathrm{C}$ by DLS. The solution was prepared at $55^{\circ} \mathrm{C}$ to obtain complete dilution and cooled down to $26^{\circ} \mathrm{C}$ before the DLS measurement. The peak indicates the aggregation of the surfactant in n-hexadecane at $26^{\circ} \mathrm{C}$.

\begin{tabular}{|c|c|c|c|}
\hline $\begin{array}{c}\text { Friction Modifier } \\
\text { (concentration) }\end{array}$ & $\begin{array}{c}\text { Temperature Range } \\
\left({ }^{\mathbf{}} \mathbf{C}\right)\end{array}$ & Peaks (nm) & FWHM (nm) \\
\hline$d i-$ FA & $26-55$ & Signal Not Found & Signal Not Found \\
\hline Charged $d i-$ FA & $26-55$ & Signal Not Found & Signal Not Found \\
\hline$t r i-$ FA & $40-55$ & Signal Not Found & Signal Not Found \\
\hline$t r i-$ FA & 26 & 4006 & 709 \\
\hline Branched $t r i-$ FA & 55 & Signal Not Found & Signal Not Found \\
\hline
\end{tabular}

Table S1: Summary of the DLS measurements on fatty amines in $n$-hexadecane at different temperatures. The detected peak for tri-FA indicates aggregation of the surfactant in $n$-hexadecane at $26^{\circ} \mathrm{C}$. The absence of peaks under all other conditions proves the dissolution of the fatty amines in $n$-hexadecane. 


\section{Supporting Information 3:}


Figure S3: Change in frequency $(\Delta f)$ and dissipation $(\Delta \mathrm{D} \times 1 \mathrm{E}-6)$ due to $d i$-FA adsorption on steel during a series-injection QCM measurement. The diagrams show similar results for before-rinse $(\mathrm{a}, \mathrm{b})$ and after-rinse (c, d) measurements across different overtones. Similar results were also obtained for the other investigated fatty amines. These observations indicate the formation of rigid, non-viscoelastic adlayers on steel surfaces. Flow rate: $75 \mu 1 / \mathrm{min}$, temperature: $55^{\circ} \mathrm{C}$. 


\section{Supporting Information 4:}

\begin{tabular}{|c|c|c|c|c|c|c|}
\hline \multirow{6}{*}{ 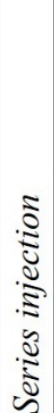 } & \multirow{2}{*}{ Friction Modifier } & \multirow{2}{*}{$\begin{array}{l}\text { Before-rinse Mass } \\
\text { adsorbed at } 0.5 \text { wt.\% } \\
\qquad\left(\mathrm{ng} / \mathrm{cm}^{2}\right)\end{array}$} & \multirow{2}{*}{$\begin{array}{l}\text { Density of the } \\
\text { friction modifier } \\
\qquad\left(\mathrm{g} / \mathrm{cm}^{3}\right)\end{array}$} & \multirow{2}{*}{$\begin{array}{l}\text { Thickness of } \\
\text { the adsorbed } \\
\text { layer }(\mathrm{nm})\end{array}$} & \multicolumn{2}{|c|}{ Number of layers on SS Surface } \\
\hline & & & & & $\begin{array}{c}\text { Perpendicular } \\
\text { orientation }\end{array}$ & Parallel orientation \\
\hline & $\mathbf{d i}-\mathbf{F A}$ & 49.2 & 0.82 & 0.6 & 0.240 & 1.61 \\
\hline & Charged di - FA & 63.8 & 0.865 & 0.74 & 0.295 & 1.98 \\
\hline & $\operatorname{tri}-\mathbf{F A}$ & 137.9 & 0.81 & 1.70 & 0.681 & 4.57 \\
\hline & Branched tri-FA & 22.8 & 0.81 & 0.28 & 0.112 & 0.75 \\
\hline
\end{tabular}

Table S2: Adsorbed mass $\left(\mathrm{ng} / \mathrm{cm}^{2}\right)$ of fatty amines obtained in series-injection QCM measurements at a concentration of $0.5 \mathrm{wt} \%$ in $n$-hexadecane. The thickness of the adlayer was estimated with the density of the friction modifiers, also shown in the table. Further, the number of FA layers on the steel surface was estimated assuming perpendicular and parallel orientations of the adsorbed molecules on the surface. 


\section{Supporting Information 5:}

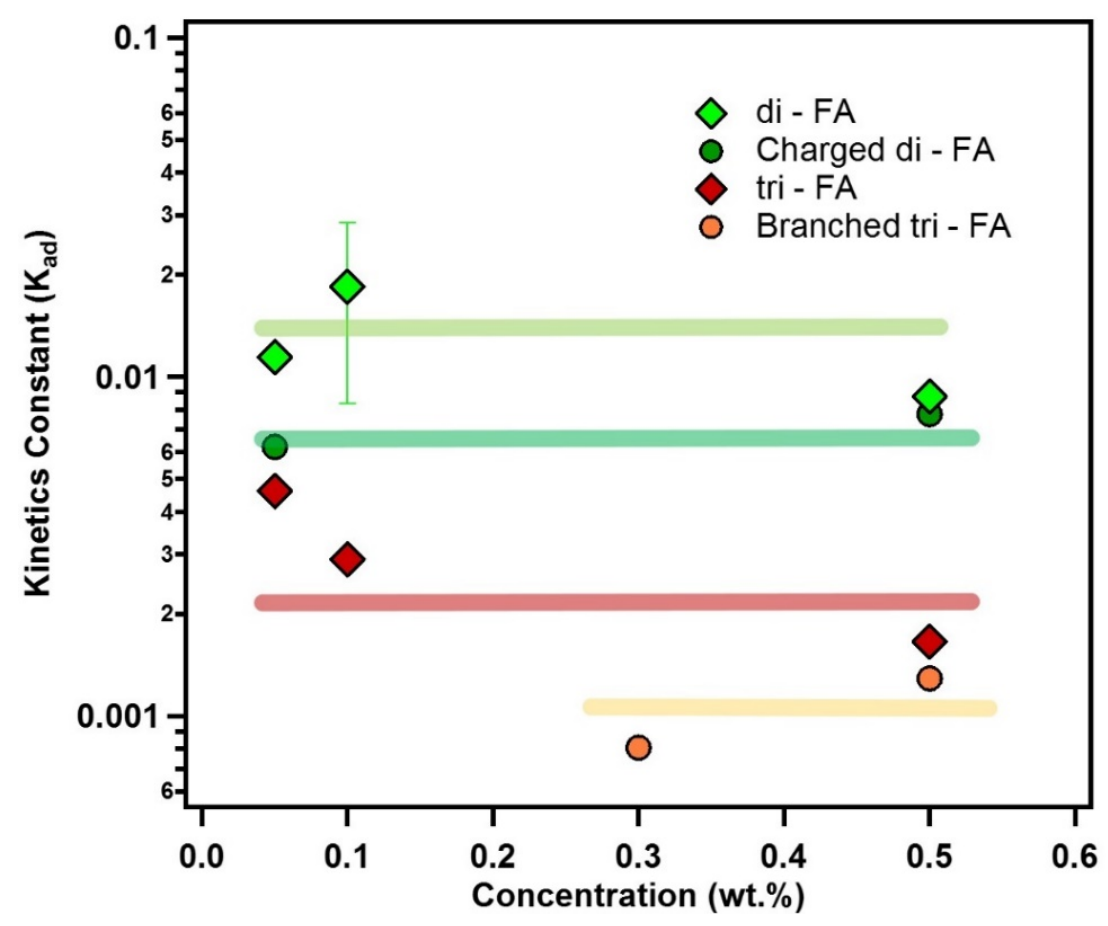

Figure S4: Adsorption rate constant $\left(\mathrm{k}_{\mathrm{ads}}\right)$ as a function of concentration of the friction modifier in $n$-hexadecane. The experimental data were fit to Eqn. 2 to determine $k_{\text {ads. }}$ The adsorption rate constant was found to be independent of the fatty amines concentration, thereby confirming the validity of a first-order adsorption kinetics to describe the adsorption of the fatty amines on steel.

\section{References:}

[1] Rodahl, M.; Kasemo, B. Frequency and Dissipation Factor Responses to Localized Liquid Deposits on a QCM Electrode. Sensor Actuat. B Chem. 1996, 37, 111-116. 
[2] Urbakh, M.; Daikhin, L. Roughness Effect on the Frequency of a Quartz-Crystal Resonator in Contact with a Liquid. Phys. Rev. B. 1994, 49, 4866-4870. 